\title{
UNIVERSIDADE PÚBLICA FEDERAL BRASILEIRA: FUTURE-SE E “GUERRA CULTURAL” COMO EXPRESSÕES DA AUTOCRACIA BURGUESA
}

\author{
ROBERTO LEHER ${ }^{1}$
}

\begin{abstract}
RESUMO: Inserido no campo das políticas educacionais, o artigo examina as medidas do governo Bolsonaro para as universidades federais, especialmente $o$ Future-se. Propugna-se que o objetivo desse programa é a refuncionalização da universidade em conformidade com os requisitos da autocracia burguesa e, o que é específico da situação brasileira, da "guerra cultural". Conclui-se indicando os fatos e relações entre eles que corroborem a continuidade dessa agenda na orientação estratégica das ações governamentais, em consonância com as expectativas de frações burguesas dominantes.
\end{abstract}

Palavras-chave: Política educacional. Universidade. “Guerra cultural”. Future-se. Governo Bolsonaro.

\section{THE BRAZILIAN FEDERAL PUBLIC UNIVERSITY: FUTURE-SE AND 'CULTURAL WAR' AS EXPRESSIONS OF BOURGEOIS AUTOCRACY}

\begin{abstract}
Inserted in the field of educational policies, the article examines Bolsonaro government's measures for federal universities, especially Future-se. It advocates that the objective of said program is to refunctionalize the university in accordance to the requirements of the bourgeois autocracy and, something specific to the Brazilian situation, the 'cultural war.' The paper is concluded by indicating the facts and their relations that corroborate that this agenda continues to strategically guide governmental actions aligned with the expectations of dominant bourgeois fractions.
\end{abstract}

Keywords: Educational policy. University. 'Cultural war'. Future-se. Bolsonaro government.

\section{LA UNIVERSIDAD PÚBLICA FEDERAL DE BRASIL: FUTURE-SE Y “GUERRA CULTURAL” COMO EXPRESIONES DE AUTOCRACIA BURGUESA}

RESUMEN: Insertado en el campo de las políticas educativas, el artículo examina las medidas del gobierno Bolsonaro para las universidades federales, especialmente

O artigo compõe a pesquisa "Financeirização da Educação: Reestruturações das Organizações Educacionais de Capital Aberto e com Participação de Fundos de Investimentos”, apoiada pelo Conselho Nacional de Desenvolvimento Científico e Tecnológico (Processo: 309524/2018-0).

1.Universidade Federal do Rio de Janeiro - Programa de Pós-graduação em Educação - Faculdade de Educação - Rio de Janeiro (RJ), Brasil. E-mail: robertoleher@fe.ufrj.br

Editor de Seção: Antonio Alvaro Soares Zuin 
Future-se. Se sostiene que el objetivo del programa es refuncionalizar la universidad de acuerdo con los requisitos de la autocracia burguesa y, lo que es específico de la situación brasileña, la "guerra cultural". Se concluye indicando los hechos y sus relaciones que corroboren que esta agenda continúe guiando estratégicamente las acciones gubernamentales, alineada con las expectativas de las fracciones burguesas dominantes.

Palabras-clave: Política educativa. Universidad. "Guerra cultural”. Future-se. Gobierno Bolsonaro.

\section{Introdução}

$\mathrm{P}$

ara compreender as medidas que, na atualidade, objetivam alterar a função social das universidades federais brasileiras, é imperioso considerar, sistematicamente, o contexto histórico-social do país, destacando, por relevância, o aprofundamento do capitalismo dependente e da correspondente autocracia burguesa (FERNANDES, 2006). Após 2018, também é preciso considerar a ofensiva da extrema direita, concebida como "guerra cultural".

A ofensiva ideológica contra as universidades federais, verificada no período das eleições presidenciais de 2018, alcançou tamanha gravidade que provocou relevante manifestação do Supremo Tribunal Federal (STF), o qual se manifestou em defesa da inviolabilidade da autonomia universitária (LEHER, 2019, p. 26-27). Após a posse de Jair Bolsonaro na Presidência da República, contudo, os conflitos assumiram maior envergadura, pois, com o poder governamental, suas palavras assumiram novos significados - lastreadas agora pelo poder de Estado. De fato, as universidades foram deslocadas para o teatro de operações da "guerra cultural" empreendida pela extrema direita e, em especial, pelo Presidente da República, por meio de diversas manifestações suas ${ }^{2}$.

No conjunto, a "guerra cultural" é um ataque à herança iluminista e aos valores da Revolução Francesa (LEHER, 2020a), objetivos explicitamente indicados por Steve Bannon, um dos mais influentes estrategistas dessa vertente da extrema direita (ALEXANDER, 2018). Por meio do negacionismo (e do anticientificismo), essa guerra objetiva abrir as vias para um regime hostil à democracia, no qual o Presidente encarne o "povo escolhido" e as suas "virtudes" (em oposição aos "traidores" do povo).

A universidade é vista como ameaça por ser uma instituição que promove a secularização da vida, o que é percebido como afronta aos valores do líder e, consequentemente, do "povo". As universidades, nos discursos governamentais, estão associadas à defesa da igualdade (democracia econômica, direitos sociais), que sacrificaria a liberdade dos indivíduos no mercado e, sobretudo, o direito do patrão de explorar livremente os "seus" trabalhadores; à explicitação da existência de classes sociais e de segmentos oprimidos e explorados (frente ao povo uno e indivisível); às causas antirracistas (negando as diferentes naturezas humanas e comprometendo a supremacia branca cristã); e às lutas contra as opressões (difundindo, assim, a denominada "ideologia de gênero"). Em suma, a universidade estaria ligada às expressões laicas de vida, que favorecem a hegemonia do "marxismo cultural", do socioambientalismo, do feminismo, do socialismo e do antirracismo. Em uma adaptação dos preceitos da "guerra cultural" no Brasil, as universidades são acusadas de estar em desconformidade com valores e comportamentos professados por "certas" interpretações do evangelho difundidas por segmentos pentecostais, neopentecostais e da Igreja Católica. A zona de conflito com a universidade e com a ciência, como é possível depreender, torna-se muito vasta e não se restringe aos embates de ideias, na forma de confrontos de argumentos.

Entre as iniciativas que pretendem refuncionalizar as universidades, é necessário colocar em destaque o Projeto de Lei (PL) n. 3076/2020, que dispõe sobre o Future-se (BRASIL, 2020b). Conforme o 
presente estudo, esse programa pretende converter as universidades em organizações utilitaristas (DARDOT; LAVAL, 2016) ajustadas às engrenagens da heteronomia cultural próprias do capitalismo dependente (FERNANDES, 1981).

Com efeito, as investigações precedentes (LEHER, 2018) procuraram sustentar a proposição gramsciana de que as ideologias não estão desencarnadas da produção material da vida (GRAMSCI, 2012, p. 41, 49-50, 184, 199). A problemática aqui exposta coloca em evidência determinados nexos entre a universidade e as atuais configurações do padrão de acumulação do capital no capitalismo dependente, configurações essas que podem se desdobrar em processos de formação protocientífica e mesmo em severo comprometimento da liberdade de cátedra.

A análise da função social das universidades requer a caracterização de aspectos que as definam como instituições sociais. Existe um forte consenso de que universidades sejam instituições direcionadas à formação complexa das novas gerações e, também, a certas formas de desenvolvimento da ciência e da tecnologia. Entre as influências que referenciaram as universidades brasileiras, é preciso colocar em relevo as concepções humboldtianas e, no caso da América Latina, o seminal movimento na universidade de Córdoba (1918), que difundiu valores e proposições relacionadas às cátedras paralelas, ao governo compartilhado da universidade, ao livre acesso à universidade e ao compromisso com os problemas nacionais, influenciando, por décadas, diversos movimentos reformistas na região (BERNHEIM, 2008) - valores esses que seguem sendo reivindicados hodiernamente. Com efeito, no Brasil, a agenda de Córdoba orientou as primeiras reivindicações de reforma universitária pela União Nacional dos Estudantes (UNE), como pode ser visto no I Seminário Nacional da Reforma Universitária (“Declaração da Bahia”, em 1961) e, sobretudo, em 1962, no II Seminário Nacional da Reforma Universitária, realizado em Curitiba (“Carta do Paraná”) (BRAGGIO, 2019). As ideias reformistas de Córdoba estiveram presentes, também, em círculos do Instituto Superior de Estudos Brasileiros (ISEB), notadamente em Carlos Estevam Martins e em Álvaro Vieira Pinto.

$\mathrm{Na}$ América Latina, a função social da universidade ganhou novos marcos, sobretudo com a defesa de que a universidade não pode deixar de interpelar os problemas nacionais e dos povos. Essa discussão nos documentos sobre a universidade elaborados na região assumiu a forma da defesa da pertinência social e do compromisso com os problemas nacionais.

O ideário de Córdoba é explicitamente reivindicado na declaração da III Conferência Regional de Educação Superior:

Frente a las presiones por hacer de la Educación Superior una actividad lucrativa es imprescindible que los Estados asuman el compromiso irrenunciable de regular a las instituciones públicas y privadas, cualquiera sea su modalidad y promoviendo la diversidad institucional, para hacer efectivo el acceso universal, la permanencia y la titulación de la educación superior, atendiendo a una formación de calidad con inclusión, diversidad y pertinencia local y regional. [...] La defensa de la autonomía universitaria es una responsabilidad ineludible y de gran actualidad en América Latina y el Caribe y es, al mismo tiempo, una defensa del compromiso social de la universidad. [...] Es por eso que creemos fehacientemente que nuestras instituciones deben comprometerse activamente con la transformación social, cultural, política, artística, económica y tecnológica que es hoy imperiosa e indispensable (UNESCO, 2018). ${ }^{3}$

No Brasil, tais definições e valores estão contidos no artigo 207 da Constituição Federal de 1988 (CF88), o qual define o próprio conceito de universidade. Em um contexto de fortes pressões para sua 
refuncionalização, é relevante retomar a discussão sobre heranças e ecos das concepções humboldtianas e da reforma universitária de Córdoba, sem, contudo, conceber tais ideias como modelos ou paradigmas, em virtude das particularidades do capitalismo dependente e da revolução burguesa no país, o que restringiu as condições para o gozo efetivo da autonomia universitária.

\section{Interpelações Humboldtianas}

A proposição de que, na universidade, o ensino e a formação são processos imbricados à pesquisa tem suas raízes modernas (ao menos como conjunto de ideias e proposições) na concepção original da universidade de Berlim - não se tratando, porém, aqui, de tomar sua criação como modelo com pretensão exemplar, um tipo ideal de universidade. Em 1961, a coalizão estudantil Der Sozialistische Deutsche Studentenbund (SDS) (NITSCH et.al. apud ÖSTILING, 2018, p. 180) salientou proposições idealistas e marcadas pelo romantismo, as quais tornam, muitas vezes, oca a expressão "universidade humboldtiana". Para sustentar a análise, os estudantes do SDS colocaram em relevo o fato de que tal concepção não interpelou, realmente, situações concretas, como o papel da ciência e dos processos de formação na sociedade de classes, profundamente alterados pela industrialização. Ademais, seus traços elitistas (a indissociabilidade artesanalmente praticada dificultaria a generalização da universidade, contribuindo para manter tal instituição como lugar de poucos), o escasso lugar conferido aos estudantes na vida cotidiana das instituições e a não realização sistemática da indissociabilidade apregoada (nem todos processos formativos estão imbricados com a pesquisa) não permitem que essa complexa concepção seja um modelo paradigmático, o que, a rigor, nunca foi seu propósito.

Entretanto, mesmo após mais de dois séculos, o debate sobre a atualidade e o futuro das universidades (especialmente sobre a função social delas) não pode deixar de se reportar a W. von Humboldt e seu conhecido texto “Sobre a Organização Interna e Externa das Instituições Superiores em Berlim", originalmente de 1810 (HUMBOLDT, 1997). Existe um núcleo de bom senso que persiste como relevante no debate atual, inclusive nos países capitalistas dependentes. Temas como a articulação ensino-pesquisa e o caráter da formação expressos na Bildung (formação humana) foram estruturantes para a concepção moderna de universidade. Cultivar o pensamento, a razão, a liberdade como liberação, a secularização e a laicidade, a autonomia, o desenvolvimento espiritual por meio da cultura (CAMBI, 1999, p. 415) e, posteriormente, no fim do século XIX e no século XX, a cidadania e a formação profissional crítica para o mundo do trabalho, referenciadas na ética pública e na autonomia universitária (relação entre universidade, Estado e economia) segue sendo axial para pensar a função das universidades no século XXI. A influência de Humboldt, e, particularmente, a compreensão da função formadora da universidade a partir da Bildung (em perspectiva histórico-social) indicam, vigorosamente, que compete ao Estado instigar, promover e assegurar meios para tal formação cultural ampla, abrangendo a ciência, a arte, a tecnologia, mas sem que isso signifique que caberia ao Estado interferir diretamente na instrução direta dos estudantes em função de interesses práticos e, principalmente, particularistas (ÖSTILING, 2018, p. 166).

As universidades modernas nasceram do racionalismo iluminista (ÖSTILING, 2018, p. 46) e, nessa perspectiva, a concepção institucional humboldtiana inseriu nessa tradição seus processos de ensino e aprendizagem, baseados no conhecimento científico e filosófico sistemáticos, assim como no campo das artes e da cultura. "As possibilidades de institucionalização da ciência moderna, liberta das tutelas da religião e da igreja, de modo a que a sua autonomia não seja posta em perigo por outras instâncias" (Estado e sociedade burguesa, interessados nos resultados úteis do conhecimento científico) (HABERMAS, 1993, p. 115), somente seriam possíveis por meio da "autonomia científica com organização estatal, que protegeria as instituições científicas contra as intervenções políticas e contra os imperativos sociais" (HABERMAS, 1993, p. 115). 
Nos anos 1960, os estudantes da SDS introduziram novos elementos, sustentando uma autonomia universitária que assegurasse a emancipação dos indivíduos, em defesa da racionalidade crítica a serviço da humanidade (ÖSTILING, 2018, p. 183). Nesse prisma, a universidade se caracteriza pela associação da formação educacional e do envolvimento da instituição com a pesquisa, levando, porém, em consideração que as demandas do capital exigem pensar a formação com base em um horizonte ético que confronte os particularismos da economia burguesa.

As questões colocadas pelo SDS abordaram, também, a democratização da gestão universitária (autogestão participativa) e do acesso à universidade nos contextos de pressão pela massificação e de induções próprias do capitalismo monopolista. Seria possível assegurá-la como direito humano fundamental, mantendo tal indissociabilidade? NITSCH et al. (apud ÖSTILING, 2018) apregoam como necessária outras indagações, sobretudo no pós-1968: "Diante da necessidade do capital de maior especialização capaz de atender às demandas do mercado, como pensar a Bildung?"; e "A especialização requerida pelo capitalismo monopolista permite que a função social das universidades seja, de fato, compatível com tal formação cultural?" As respostas a tais interpelações exigem pensar a herança humboldtiana de modo crítico à adaptação passiva aos imperativos capitalistas. O SDS propugnava a renovação crítica do ideário humboldtiano, assegurando, centralmente, a "autonomia da ciência" como valor constitutivo da universidade, fazendo frente aos possíveis intentos autoritários do Estado (HABERMAS, 1993).

No Brasil, os ventos renovadores da reflexão crítica da herança humboldtiana engendrados pelo SDS e outros movimentos estudantis, no bojo das lutas protagonizadas pelos estudantes em 1968, não alcançaram os agentes envolvidos na chamada reforma universitária. Os debates sobre a universidade humboldtiana foram apropriados pelos intelectuais conservadores a serviço da ditadura empresarial-militar, no contexto do ambiente de regulamentação da pós-graduação, em 1965, e, principalmente, na dita reforma universitária, de 1968, em sentido inequivocamente contraditório à autonomia universitária e à liberdade de cátedra - vide o AI-5/1968 e o Decreto n. 477/1969 (CUNHA, 2007). A contrarreforma também buscou afastar as universidades de sua missão de pertinência, forçando o silenciamento das problemáticas de pesquisa que buscavam responder aos grandes desafios sociais: determinantes do subdesenvolvimento e da pobreza; desigualdade social; tecnologia e soberania nacional etc. Na mesma linha, o Banco Mundial atacou, mais recentemente, nos anos 1990, a tradição humboldtiana por meio do combate ao chamado modelo europeu de universidade, proposição sustentada, notadamente, no conhecido documento La Ensenãnza Superior: Las Lecciones Derivadas de la Experiência (BIRD, 1995) discutido adiante.

É justamente a partir dos parâmetros neoliberais, erigidos a partir dos anos 1990, que o governo Bolsonaro, após institucionalização de um novo marco para a autocracia burguesa - o golpe de 2016 (MIGUEL, 2019) -, está construindo as condições para impor uma profunda refuncionalização das universidades. As concepções de autonomia e função social, herdeiras do iluminismo e das ideias humboldtianas, assim como o compromisso com os problemas dos povos, tornaram-se, hodiernamente, alvo da "guerra cultural" empreendida pela extrema direita no Brasil: o teatro de operações da "guerra cultural" foi explicitamente deslocado para o ambiente universitário.

\section{Agenda Hostil à Indissociabilidade entre o Ensino, a Pesquisa e a Extensão e à Autonomia Universitária}

Em que pesem os princípios liberais que caracterizaram o discurso do II PND e o do II Plano Básico de Desenvolvimento Científico e Tecnológico (PBDCT), havia claramente uma proposição intervencionista que ia muito além da ação sobre as assim chamadas falhas de mercado (SALLES FILHO, 2003, p. 181). 
O intento de alterar as prioridades das universidades públicas, presente no período ditatorial, foi efetivo, conformando a expansão da pesquisa e da pós-graduação. O contexto das mudanças nas universidades do último quarto de século é outro. De modo ainda mais incisivo e direcionado, foi a partir da consolidação do sistema de acumulação neoliberal (SAAD FILHO; MORAIS, 2018) que a função da universidade, referenciada na indissociabilidade entre o ensino, a pesquisa e a extensão e, institucionalmente, na autonomia universitária, passou a ser considerada anacrônica e inviável.

As medidas do período neoliberal seguiram afastando as universidades dos grandes problemas nacionais, sob pretexto de que a pesquisa de grandes complexos temáticos, por exigir a investigação de múltiplas relações e determinações, seria, a priori, desprovida de mérito científico, tal como apregoado pelas organizações internacionais que redefiniram o campo das ciências sociais e do fazer científico em geral.

Nos anos 1990, o Banco Mundial sistematizou uma série de proposições sobre a educação superior do chamado "mundo em desenvolvimento" na publicação La Ensenãnza Superior: Las Lecciones Derivadas de la Experiência (BIRD, 1995). O documento combateu o chamado modelo europeu de universidade, direcionando suas críticas ao modelo humboldtiano. Em que pese ajustes aqui e acolá, a publicação se afirmou, nos últimos 25 anos, como matriz de sua análise sobre o tema e guia de sua estratégia. A proposição é direta: "El modelo tradicional de universidad europea de investigación, con su estructura de programas en un solo nivel, ha demostrado ser costoso y poco apropiado en el mundo en desarrollo" (BIRD, 1995, p. 15, 31).

O Banco Mundial atribui às universidades dos países ditos em desenvolvimento baixo índice de atividades de pesquisa e desenvolvimento, o que, rigorosamente, não é verdadeiro - recente estudo de Brito da Cruz (VASCONCELOS, 2020) nos mostra que o percentual de artigos das universidades brasileiras em coautoria com empresas é muito semelhante ao das universidades da União Europeia (2,5\%). Tal proposição ignora, ademais, a dinâmica do desenvolvimento tecnológico no capitalismo dependente e as formas específicas de associação entre as frações burguesas locais e as frações burguesas hegemônicas, que, em geral, não deslocam seus departamentos de tecnologia para os países ditos periféricos. Como será visto adiante, o esquema interpretativo do Banco perpassa todo o PL do Future-se.

A refuncionalização das universidades como organização de serviços empenhadas na difusão do ethos do empreendedorismo - inscrito na lógica da pejotização e da uberização do trabalho (KREIN et al., 2018) (por "pejotização" entenda-se assalariado como Pessoa Jurídica [PJ] e, por "uberização", trabalho autônomo sem direitos trabalhistas) -, como quer o PL do Future-se, abre caminho para corte de gastos na educação superior, visto que a formação massiva e desvinculada de ambientes de pesquisa envolve menor custo, podendo, inclusive, ser realizada por meio de Educação a Distância (EaD). Ao mesmo tempo, essa refuncionalização pretende regular o fluxo da força de trabalho, preparando os indivíduos para o autoempreendedorismo, medida crucial para o objetivo do capital de desregulamentar o conjunto da força de trabalho - afinal, o autoempreendedorismo pode abranger tanto o trabalho de maior complexidade (sobretudo pela "pejotização") quanto as funções de menor sofisticação ("uberização"), tema que será retomado adiante.

O intento de refuncionalização das universidades é autocrático. O Governo Federal tentou, por meio da Medida Provisória (MP) n. 979, de 9 de junho de $2020^{4}$, impor reitores biônicos, indicados diretamente pelo Presidente da República. Foi nesse ambiente hostil à indissociabilidade, à autonomia e ao compromisso com os problemas dos povos que o governo Bolsonaro encaminhou as três versões do Future-se ${ }^{5}$ e, recentemente, o correspondente PL: a extrema direita ultraneoliberal, desse modo, oferece pistas sobre a desconhecida agenda em curso. 


\section{Teor e Objetivos do Projeto de Lei do Future-se}

O Projeto de Lei que "Institui o Programa Universidades e Institutos Empreendedores e Inovadores - Future-se" (publicado no site da Casa Civil no fim de maio de 2020, numerado na Câmara como PL n. 3076/2020 e protocolizado no dia 2 de junho de 2020) foi lançado poucos dias antes da exoneração do Ministro da Educação Abraham Weintraub, em 20 de junho de 2020, investigado em inquéritos no STF por ofensas à ministros da corte, pela disseminação de fake news e, também, por crime de racismo.

Como salientado em estudos prévios sobre o tema (LEHER, 2020a, 2020b), o PL tem de ser examinado em seu inteiro teor, articulando seus artigos, parágrafos e incisos em um único corpus analítico. O exame da Exposição de Motivos (EM) de 03 de abril de 2020 (BRASIL, 2020a), que justifica tal projeto, é indispensável, assim como a complexa conjuntura econômica, política e sanitária do país.

O Future-se está inserido no contexto da estratégia da "guerra cultural" (LEHER, 2020a). Como toda estratégia, existem movimentos táticos, avanços e recuos. A presente investigação foi realizada à luz das versões anteriores do projeto, buscando identificar o que permanece e o que foi abandonado (GIOLO, LEHER, SGUISSARDI, 2020). O debate nacional sobre o tema foi muito bem-mapeado no dossiê do Grupo de Pesquisa Trabalho, Precarização e Resistências da UFBA (GRUPO..., 2019). Diversos Conselhos Universitários produziram documentos muito relevantes que igualmente merecem estudo sistemático (SALLES, 2019). Em todas essas publicações e manifestações, é possível identificar elementos constitutivos do projeto em curso para a educação no país.

A apresentação do PL ao Congresso no contexto de agravamento da pandemia é um gesto a ser considerado. Ocupa o lugar de medidas que deveriam estar sendo adotadas pelo Ministério da Educação (MEC) a fim de viabilizar melhor infraestrutura de pesquisa para o enfrentamento da pandemia e, também, de viabilizar o retorno futuro das atividades acadêmicas presenciais - medidas como novas salas de aula, gabinetes de trabalho e espaços de convivência em conformidade com as normas de biossegurança que não favoreçam a propagação do Sars-CoV-2. Também não se preconiza um plano integrado de construção de novos laboratórios multiusuários a fim de ampliar a capacidade de pesquisa sobre temas conexos à pandemia. É inequívoco que tal medida está em linha com o negacionismo próprio da citada "guerra cultural".

A relevância desse deslocamento de agenda pode ser mensurada pelo ambiente econômico. A pandemia agrava ainda mais a crise econômica, o que repercutirá de modo extremamente grave na receita proveniente dos impostos que lastreiam as vinculações constitucionais para a educação - situação magnificada pelos efeitos sistêmicos negativos da Emenda Constitucional (EC) n. 95/2016. O PL referente ao Future-se pretende estabelecer que a única alternativa viável para o financiamento das universidades será a captação de recursos no mercado, por meio de projetos relacionados ao empreendedorismo e à inovação tecnológica. O busílis do problema - o crônico subfinanciamento público - perde centralidade na agenda política do país e, o que é extremamente grave, na pauta das próprias universidades.

\section{Continuidades e Diferenças em Relação às Versões Anteriores do Future-se}

O exame do texto preliminar do PL n. 3076/2020 permite asseverar que este:

[...] está inscrito na "guerra cultural", é hostil à ciência, à autonomia universitária e à liberdade de cátedra. Reafirma a definição estratégica de refuncionalização das instituições em "organizações" empreendedoras e inovadoras em um ambiente produtivo em que a 
pesquisa e desenvolvimento (P\&D) é escassa, desprovida de originalidade e minguante. Por meio de adjetivações (empreendedora e inovadora), almeja mudanças na função social das universidades frente aos problemas dos povos, aos desafios democráticos - políticos e econômicos - da nação e aos problemas lógicos e epistemológicos do conhecimento (LEHER, 2020b).

O PL final é mais enxuto do que as três versões anteriores. Em decorrência das críticas de conselhos universitários, sindicatos e partidos políticos, taticamente, o governo alterou pontos importantes do texto, objetivando sua aprovação no Congresso. Entre as modificações, exclui do texto a possibilidade de alienação de patrimônio; os contratos de gestão ancorados em organizações sociais em conexão com fundos de investimentos; e, também, a criação de sociedades de propósito específico. Abstêm-se de modificar um conjunto de leis, como a que permitiria a abertura da Empresa Brasileira de Serviços Hospitalares (Ebserh) aos planos de saúde (Lei n. 12.550/2011) e o reconhecimento dos diplomas estrangeiros pelo setor privado (alterando a Lei n. 9.394/1996).

A exemplo das versões anteriores, o PL final foi elaborado sem nenhum estudo ou diagnóstico da situação das universidades e dos institutos. Ignora as séries históricas de financiamento, sobretudo de custeio e capital; a expansão das universidades e institutos; a capacidade instalada de pesquisa; a situação dos parques tecnológicos; a situação do fomento à área de ciência, tecnologia e inovação; o perfil social dos estudantes e a assistência estudantil; a infraestrutura e a depreciação das instalações; e a existência do patrimônio tombado pelo IPHAN, entre outros. A ausência de estudos diagnósticos oculta os problemas, distorce os desafios a enfrentar e naturaliza uma agenda hostil à autonomia universitária e dos institutos.

Em relação ao financiamento, a investigação preliminar do teor do PL colocou em relevo o fato de que a não realização de estudos orçamentários para fundamentar o texto do Future-se oculta uma grave realidade:

A análise da série histórica do orçamento de outros custeios e capital das universidades e institutos federais [...] permitiria evidenciar que, entre 2013 e 2019 [...], o orçamento de capital (investimentos), em valores constantes, foi reduzido quase a zero e, também, que os recursos de custeio sequer permitiram o pagamento das contas mais cotidianas, como energia, limpeza, transporte, segurança, estrangulando as verbas de manutenção estrutural (LEHER, 2020b).

A averiguação do Programa Nacional de Assistência Estudantil, igualmente, colocaria em destaque a insuficiência das verbas da assistência estudantil, justamente em um contexto em que os estudantes pauperizados mais necessitam de suporte. A queda relativa dos recursos de ciência e tecnologia foi ainda maior: os recursos somados do CNPq, do FNDCT e da FINEP despencaram de R 13 bilhões, em 2015, para R 6 bilhões, em 2019. O PL ignora a situação dos parques tecnológicos; as leis de incentivo a pesquisa e desenvolvimento; a privatização de empresas que possuem engajamento em pesquisa e desenvolvimento, como Petrobras e Embraer; e a desconstituição de importantes cadeias produtivas que poderiam agregar tecnologia original (CARVALHO, 2020). Desse modo, é um instrumento legal que opera, efetivamente, no terreno das ideologias - lembrando sempre que elas têm dimensão material.

Pelo fato de o Future-se fazer tábula rasa sobre o orçamento, é preciso lançar luz sobre os recursos que ele preconiza como atrativos do PL. Anteriormente, havia a indicação fantasiosa, pois essencialmente contábil, de um fundo de R 100 bilhões, o qual desapareceu do PL final ${ }^{6}$. Não apenas inexistem recursos novos, como também o PL é feito para moldar o orçamento do MEC às restrições da "lei de ferro" instituída 
pela EC n. 95/2016, as quais, em virtude da atual crise, serão ainda mais draconianas. Indicadores do FINEDUCA (2020) mostram que, apenas em 2019, sem o aprofundamento da crise em virtude da pandemia, a emenda em questão retirou $\mathrm{R} \$ 32,6$ bilhões da educação. A redução vertiginosa da receita de impostos, decorrente da forte queda dos PIB de 2020 e 2021, agravará ainda mais o desfinanciamento do setor federal. Sem qualquer lastro empírico, como visto, o PL do Future-se anuncia a promessa de que o setor privado aportará vultosas somas de recursos para universidades e institutos:

Excetuando os casos clássicos, Petrobras e Embraer, e mais um punhado de empresas, não há interesse real das empresas localizadas no Brasil em constituir departamentos de $\mathrm{P} \& \mathrm{D}$ próprios; tampouco elas projetam uma inserção no mercado local e mundial a partir do desenvolvimento de novas tecnologias e processos (LEHER, 2020b).

Em virtude do aprofundamento das bases do capitalismo dependente - expropriações e superexploração do trabalho - e da desconstituição de cadeias produtivas intensivas em conhecimento, "não é realista acreditar que a fonte desses recursos privados (previstos no art. 1, inciso I) será proveniente das mineradoras (em territórios indígenas?), do agronegócio, [...] e de outros segmentos [...] hostis à universidade pública" (LEHER, 2020b). No Brasil, são raras as empresas que possuem departamentos de P\&D e que contratam doutores. A demanda das empresas, quando existe, não é de inovação tecnológica, mas, em geral, de serviços (LEHER, 2020b).

A EM que referencia o PL n. 3076/2020 admite que o Novo Regime Fiscal obstaculiza o financiamento público ${ }^{7}$ :

Diante do que é considerado um "dado da realidade", o governo aponta que a única alternativa é o mercado. A despeito da promessa de que os recursos são suplementares ("Importante ressaltar que fontes privadas adicionais não alteram a destinação de recursos orçamentários às universidades e institutos federais", EM), "torna-se indispensável que as IFES impulsionem suas fontes adicionais de recursos. O Future-se nada mais é do que uma política voltada a melhorar as condições institucionais para que isto ocorra" (EM) (LEHER, 2020b).

O texto da EM trabalha com duas premissas. Primeira, em virtude das restrições estabelecidas pela EC n 95, é indispensável “a captação no mercado, como se isso fosse desejável e possível” (LEHER, 2020b). A subordinação dos fins da universidade à obtenção de recursos no mercado, por meio de processos dissociados de circuitos que envolvam nexos entre a pesquisa universitária e $\mathrm{P} \& \mathrm{D}$ realizado nas empresas, pode destruir o patrimônio universitário brasileiro e, também, as conquistas científicas e tecnológicas. A segunda premissa é de que, é crucial frisar, os eventuais recursos captados pelo Future-se não serão para a melhoria dos investimentos da instituição em geral, mas para os projetos específicos de interesse dos financiadores das pesquisas, que, em geral, oneram o custeio da instituição, em virtude do gasto adicional com energia, segurança, água, limpeza etc.

Em conformidade com o Plano Diretor da Reforma do Estado e seus desdobramentos posteriores, o PL do Future-se está ancorado na figura jurídica do contrato de gestão, agora repaginado, mais neoliberalizado, como "contrato de resultado" (PL, arts. 3 e 5). "O programa Future-se prevê, em sua essência, que as universidades e os institutos federais celebrarão contrato de resultado com a União, por intermédio do Ministério da Educação, como condição para a participação do Programa" (EM, item 13). O modus operandi do PL é característico das políticas autocráticas: 
Ninguém é obrigado a aderir ao programa, mas tem que aderir. As [universidades] que não aderirem serão penalizadas. Somente as instituições que celebrarem o contrato de resultado terão acesso aos prometidos recursos e facilidades adicionais e, é preciso ressaltar, às bolsas da CAPES adicionais8. A distribuição desigual dos recursos e bolsas da CAPES é flagrantemente hostil à autonomia universitária e aos princípios republicanos contidos na Carta Magna: mas esse é o projeto em curso (LEHER, 2020b).

Ademais, o contrato de desempenho pressupõe subordinação da universidade às novas orientações do Ministério da Ciência, Tecnologia, Inovações e Comunicações (MCTI) (PL, art. 1), que, hodiernamente, afrontam a liberdade de cátedra das universidades:

Esta é uma das formas para converter o Future-se em instrumento da "guerra cultural" em curso e que possui uma de suas casamatas no MEC, manobra que conta com o silêncio obsequioso e aquiescente do MCTI. ${ }^{9}$ Por isso, é tão importante que o controle do processo esteja estritamente centralizado no Poder Executivo (PL, arts. 8 e 9) ${ }^{10}$ (LEHER, 2020b).

O PL, nesse sentido, é um instrumento legal, que objetiva esvaziar toda força constitucional do preceito da autonomia universitária, tornando-a mera reminiscência formal do art. 207 da CF88, incapaz de assegurar a liberdade de cátedra, o autogoverno e a força autonormativa dele decorrente (FERRAZ, 1998).

Nos termos do art. 4, o Programa Future-se se divide em três eixos: 1) pesquisa, desenvolvimento tecnológico e inovação; 2) empreendedorismo; e 3) internacionalização. A seguir, cada um destes eixos será examinado de modo mais sistemático, especialmente os dois primeiros, em virtude da centralidade para a lógica do PL.

1. Pesquisa, desenvolvimento tecnológico e inovação. O texto repete, de modo desconexo, diversos dispositivos da Lei de Inovação Tecnológica e do Marco Legal de Ciência e Tecnologia. Na ótica governamental, a relação das universidades com o setor produtivo "ainda parece ser tabu" (EM, item 20), "ignorando o já consolidado e largo espectro dessas interações que somente não são mais amplas em virtude da descomplexificação das cadeias produtivas no país” (LEHER, 2020b). Entretanto, o PL agrega elementos preocupantes, inscritos no objetivo geral de refuncionalização das instituições. É preciso destacar a postura pró-corporações multinacionais. No art. 18, está presente a defesa da "cultura de proteção da propriedade intelectual", como se essa fosse um dogma e um fim em si mesmo:

A própria Organização Mundial da Saúde (OMS) abriu a discussão sobre o não patenteamento da futura vacina para a Covid-19. Trata-se de um esforço em prol das corporações ou da preservação de vidas? Ademais, o problema de fundo não está restrito às patentes, mas, sobretudo, às participações na produção em escala dos processos e produtos desenvolvidos com a participação das instituições, significativamente não abordado pelo projeto (LEHER, 2020b).

Há outro problema relevante nesse eixo: a proposição de que os laboratórios multiusuários, primariamente, atendem às empresas é imprópria. Mesmo laboratórios que incorporam demandas de empresas não podem deixar de estar direcionados para os fins da universidade. O convênio da British Petroleum (BP) com as universidades da Califórnia e de Illinois (2007) ilustra o controle das corporações sobre o fazer universitário: 
A BP doou uma enorme soma de recursos, US\$ 500 milhões, para constituir a maior unidade de pesquisa em uma universidade: Energy Biosciences Institute (EBI). Nos documentos de 2007, estava previsto que a EBI seria dirigida por um diretor selecionado pela BP e aprovado por um painel conjunto da BP, Berkeley e Universidade de Illinois em Urbana-Champaign (UIUC). O diretor adjunto seria sugerido pela empresa, o que expressa que a BP teria mais influência sobre a alocação de financiamentos e da direção de pesquisas do que quaisquer das instituições públicas. Ademais, cinquenta pesquisadores seniores da BP comporiam a equipe do EBI, ampliando a esfera da ingerência e de controle no cotidiano do fazer científico (LEHER, 2020b).

"O estreito controle da BP sobre o EBI da Universidade da Califórnia - Berkeley seria ainda maior em um país capitalista dependente; entretanto, os montantes não seriam os mesmos" (LEHER, 2020b). De fato, os departamentos de P\&D mais estratégicos das maiores corporações raramente são deslocados para as suas filiais na América Latina, por exemplo.

Distintamente, a perspectiva da autonomia universitária, anteriormente discutida (autonomia da ciência), corrobora a tese de que os laboratórios das instituições universitárias devem seguir por elas dirigidos; ou seja, orientados pelos debates éticos, epistemológicos e científicos da instituição. Tal proposição não é incompatível com convênios que permitam agregar conhecimento original a determinados domínios tecnológicos, fortalecendo a aplicação da ciência em cadeias produtivas, a exemplo do complexo industrial da saúde. Em oposição às concepções do Future-se sobre a ideologia inovacionista, esvaziada de fundamentos científicos, utilitarista, estruturalmente heterônoma, a reflexão universitária sobre a tecnologia pode estar referenciada na epistemologia da técnica a que se referiu Álvaro Vieira Pinto (2013), em que a própria tecnologia e seu sentido social, sobretudo para a soberania do país em domínios estratégicos, assumem lugar proeminente na agenda da instituição.

A hipertrofia da racionalidade técnica é uma forma de manejar, por meio das políticas de ciência e tecnologia, bem como do financiamento, as agendas da pesquisa e de ensino e extensão (nesses casos, pela ideologia do autoempreendedorismo), inviabilizando, desse modo, temas relacionados à questão socioambiental, aos povos indígenas, ao racismo, à soberania alimentar, à educação laica, entre outros. O intento de suprimir os problemas éticos, os valores sociais e a projeção de novas possibilidades de bem-viver dos povos deforma a função social da universidade como lugar da formação humana sistemática. Como salienta Einstein, "o método científico não nos pode ensinar outra coisa além do modo como os fatos se relacionam e são condicionados uns pelos outros" (EINSTEIN, 1994, p. 25). O problema, segue o cientista, é que "o conhecimento do que é não abre diretamente a porta para o que deve ser" (EINSTEIN, 1994, p. 21-22), abrindo vias para as aspirações humanas, as metas e as utopias que constituem os cenários de futuro. Daí o motivo de o positivismo ser conservador: interdita o porvir e a possibilidade de rupturas no continuum do tempo. Na estratégia da "guerra cultural", os valores estão definidos pelas práticas cristãs interpretadas por correntes fundamentalistas, inscritas na divinização da nação ("Brasil, acima de tudo; Deus acima de todos") e do próprio líder, alçado à condição de "mito". No prisma da "guerra cultural", a universidade, quando se apropria da ciência, da tecnologia, da arte, da cultura e dos saberes socialmente construídos nas relações humanas transformadoras para projetar possibilidades de futuro, estaria sendo ideológica, "partidária" e guiada pelo chamado "marxismo cultural". Contudo, os adeptos da "guerra 
cultural" incentivam que a religião ou o mito imponha sua versão sobre os "fatos e relações entre os fatos", que são domínios próprios da ciência.

2. O (auto)empreendedorismo está inserido no PL do Future-se como o cimento ideológico que materializa a "guerra cultural". O PL se apropria dessa noção para interferir na formação da consciência dos estudantes, difundindo a ideologia de que os não possuidores de bens podem ser, eles mesmos, capitalistas empreendedores. Propugna que a cultura autoempreendedora é uma solução para a empregabilidade e a redução da evasão (PL, art.1; EM, item 21): "[empreender para] a construção do próprio futuro; isto é, de gerar capital social e capital humano." O texto assume que a não assimilação da chamada "cultura empreendedora" acarreta maior evasão e baixa empregabilidade. Não há estudo ou evidência para que isso seja afirmado: opiniões são erigidas à condição de conhecimento equiparável à ciência.

O autoempreendedor é relexicalizado como um sujeito que, se lograr condições de institucionalização, será uma pessoa jurídica, originando, como assinalado, um neologismo: a pejotização:

O processo de pejotização envolve uma série de elementos associados às transformações do trabalho observadas nas últimas décadas, em uma perspectiva global; dentre eles: 1) as ameaças do desemprego e as consequentes pressões sobre o trabalhador, que minam as possibilidades de resistência; 2) a possibilidade de transferir para o trabalhador o próprio gerenciamento sobre seu trabalho, sem que isto signifique eliminar a relação de subordinação ou a perda de controle sobre o trabalho; 3 ) as pressões por desregulamentação da jornada de trabalho combinada com a crescente indistinção entre o que é e o que não é tempo de trabalho (FILGUEIRAS et al., 2018, p. 104).

A inserção do autoempreendedorismo no fulcro da função social da universidade estabelecida pelo PL está em contradição com a liberdade de cátedra e deforma a função social da universidade:

Art. 19, VI - Promover e disseminar a educação empreendedora por meio da inclusão de conteúdos e atividades de empreendedorismo nas matrizes curriculares dos cursos técnicos, de graduação e de pós-graduação, nos termos do disposto na política institucional de inovação.

O propósito de refuncionalizar a própria matriz curricular é explícito. As matrizes curriculares sistematizam e organizam o rol de problemáticas científicas, tecnológicas e culturais de uma dada formação. $\mathrm{O}$ autoempreendedorismo requer a exacerbação, sem precedentes, do individualismo; cada estudante deve ser preparado para competir no mercado. Os que melhor gerenciarem seus empreendimentos serão os que sobreviverão na "selva do mercado".

Desde já, é necessário desfazer dois equívocos. A ideologia do autoempreendedorismo nada tem a ver com o engajamento da universidade e de seus estudantes em novas estratégias produtivas em prol do bem-viver dos povos - mesmo porque inexistem cadeias produtivas que alavanquem, de modo duradouro, tais iniciativas econômicas. Tampouco essa ideologia está relacionada à imprescindível interpelação do mundo do trabalho e de suas transformações. Como apontado no tema da tecnologia, é imperioso que a universidade seja uma instituição 
capaz de pensar o trabalho humano e suas interações com a ciência, a tecnologia, a arte, a cultura e as práticas sociais. Tal função, contudo, não pode ser substituída por preceitos ideológicos sobre o empreendedorismo, em geral difundidos em "literatura de aeroporto":

A ideologia empreendedora não tem a ver com criação e sistematização de estudos, projetos e iniciativas voltados para domínios tecnológicos, fomento de cadeias produtivas, superação de obstáculos tecnológicos para determinados fins, reconhecidos como pertinentes e legítimos pelas instituições. A compreensão plena, complexa, sobre os aspectos tecnológicos, organizacionais, culturais, econômicos, sociais, ambientais, entre outros, relacionados ao metabolismo econômico-social da vida, é necessária e cada vez mais estratégica, não podendo, por isso, ser reduzida às ideologias vulgares em circulação no capitalismo atual (LEHER, 2020b).

3. Internacionalização. Essa seção é eivada de platitudes que pululam no texto, como "promover a inovação em conformidade com a sociedade globalizada". Aparentemente, o PL parece ter esquecido que o governo Bolsonaro é antiglobalização, definida como "perigoso globalismo". As agendas de pesquisa mais mundializadas, a exemplo das mudanças climáticas globais, são tidas como "climatismo", uma expressão do marxismo cultural; a pandemia da Covid-19 é vista como uma conspiração chinesa que, na vida real, não tem qualquer relevância; e assim sucessivamente. Além da subordinação aos preceitos do Presidente dos EUA, o governo Bolsonaro é estritamente isolacionista; por isso, a agenda da internacionalização é uma contradição em termos. Para não deixar margem a dúvidas, o PL do Future-se reafirma a obediência devida às novas políticas de ciência e tecnologia empreendidas pelo bolsonarismo, cristalizando as relações assimétricas EUA-Brasil tão ardorosamente defendidas pelo Ministério das Relações Exteriores. Além das obviedades, nada que permita melhorias na colaboração e nos compartilhamentos internacionais, por meio de coalizões, uso de infraestrutura comum, aperfeiçoamento da mobilidade de estudantes e servidores, entre outros.

\section{Considerações Finais}

$\mathrm{Na}$ autocracia da ditadura empresarial-militar, a chamada "reforma universitária" teve como objetivos, ao mesmo tempo: 1) a subordinação das universidades ao capitalismo monopolista então em estruturação - como é possível depreender dos Planos Nacionais de Desenvolvimento (PND), do arcabouço da Lei n. 5.540/1968 e dos PBDCT; 2) o expurgo dos intelectuais marxistas e, genericamente, de todos os críticos à ditadura, por meio do AI-5/1968 e do Decreto n. 477/1969, e mesmo o assassinato de professores e estudantes que se engajaram nas lutas contra a ditadura; 3) a nomeação de reitores afins ao regime, ignorando as escolhas preferenciais dos Conselhos das instituições; 4) a imposição de restrições ideológicas na seleção de docentes, em linha com a doutrina da segurança nacional; e 5) aprofundar, de modo estrutural, a heteronomia das universidades frente ao Estado, por meio da subordinação de toda agenda de pesquisa ao aparato de ciência e tecnologia operacionalizado pelas linhas de pesquisa e, mais tarde, pelos editais, direcionando recursos de modo diferenciado para os setores considerados prioritários pela ditadura. Esses foram os fundamentos da atual pós-graduação no país, que, a rigor, não foram submetidos a rigorosa avaliação, democraticamente realizada, de modo a promover indispensáveis descontinuidades com a política educacional da ditadura. 
A reaglutinação, no final dos anos 1970, de organizações diversas possibilitou maior "ocidentalização" da sociedade civil brasileira, inicialmente por entidades representativas do mundo empresarial, visto que os sindicatos e os principais movimentos sociais estavam proscritos pela ditadura. O gradual fim da censura aos meios de comunicação e, após o ressurgimento das greves do gim dos anos 1970, a criação de entidades vinculadas à classe trabalhadora - processos que culminaram na CF88 - pareceram para muitos uma tendência que resultaria, necessariamente, no desmonte de todo arcabouço de classe da autocracia burguesa. Essa não foi a análise de Fernandes, elaborada em A Revolução Burguesa no Brasil (FERNANDES, 2006). Nessa obra, a autocracia está indissoluvelmente relacionada ao capitalismo dependente: sem rupturas, as bases da autocracia, em sua análise, permaneceriam ativas. O golpe em 2016 escancarou a debilidade da democracia no Brasil e evidenciou que, em caso de crise severa, o bloco no poder não hesita em erigir saídas edificadas sobre os escombros da democracia e dos direitos sociais. A EC n. 95 e a contrarreforma trabalhista confirmam a proposição.

O problema da escalada antidemocrática é que as feições da autocracia e as condições de seu exercício ganham dinamismo próprio. Não há como regular tempos, movimentos e espaços. Nesse ambiente, as circunstâncias favoreceram a eleição de Jair Bolsonaro a partir de uma agenda de extrema direita que, para se viabilizar, é acionada permanentemente pelo Presidente. Desse modo, ele mantém sua base social mobilizada e naturaliza os termos da "guerra cultural". Atualmente, muitos autores (BOITO JR., 2019; MATTOS, 2020; MÜLLER, 2020) propugnam que está em curso uma agenda balizada no neofascismo, formulação que encontra forte lastro histórico e factual. O método de afirmação dessa agenda é, todo ele, referenciado nas práticas negacionistas e anticientificistas (ciência como ficção verbal), bem como por meio de ameaças abertas ou veladas, inclusive de ruptura com o estado democrático de direito. A compreensão dos ideólogos da "guerra cultural", como Steve Bannon e seu intérprete local, o ideólogo da família presidencial, Olavo de Carvalho, é de que somente pode haver vitória contra o chamado "marxismo cultural" - climatismo, ideologia de gênero, entre outros - se, e somente se, os pilares do iluminismo (daí o ódio à Escola de Frankfurt e ao gramscianismo) e os valores da Revolução Francesa forem destroçados. Esse é movimento tático em curso do Governo Federal sobre as universidades federais.

Com efeito, o MEC foi convertido em uma casamata da "guerra cultural". O ex-Ministro Abraham Weintraub representa exemplarmente esse processo. Foi por sua iniciativa, e com sua aquiescência, que o Future-se foi introduzido na agenda do MEC com o preciso objetivo de refuncionalizar universidades e institutos federais. Para operar a refuncionalização da universidade é preciso ressignificar a autonomia universitária como "autonomia financeira". Conjugando asfixia orçamentária e induções para que as instituições caminhem com os próprios pés, é possível incidir sobre a autonomia e a função social herdada de distintas inspirações, como as ideias humboldtianas e da reforma universitária latino-americana referenciada em Córdoba. A captação no mercado, nessa vertente, é peremptória. Por meio de imperativos econômicos, o Future-se pretende alterar a agenda e a vida cotidiana das instituições. A estruturação de projetos nesse âmbito é heterônoma, sempre subordinada ao MEC e às suas decisões arbitrárias. A subordinação ao ethos privado-mercantil, nos termos do PL em questão, é um meio para alcançar os propósitos mais profundos do Future-se: a refuncionalização da universidade, sobressaindo ideologias como o autoempreendedorismo.

$\mathrm{Na}$ ótica da "guerra cultural", expressa por seus objetivos de longa duração, a transformação da função social da universidade pela supremacia do autoempreendedorismo é a melhor forma de afastar da vida acadêmica a autonomia da ciência, a formação cultural ampla e a recusa da neutralidade ética da pesquisa.

Por tudo isso, o Future-se é contestado pela imensa maioria de Conselhos Universitários, movimentos estudantis, sindicatos, organizações científicas e coletivos partidários que possuem compromisso com a autonomia universitária. Nessas resistências e proposições alternativas, emergem traços de uma plurifuncional agenda que anuncia a recontextualização crítica da herança iluminista que sustenta a liberdade de cátedra e a 
liberdade de pensamento como fundamentos da vida acadêmica. São essas concepções polissêmicas, muitas vezes esvaecidas pelas dificuldades conjunturais, que motivam as lutas públicas em prol da universidade pública, laica, gratuita e comprometida com os problemas dos povos. As interpelações advindas da pandemia, nesse sentido, podem ensejar um processo impulsionador de novas problemáticas científicas, sociais e econômicas que possibilitem a atualização da função social das universidades públicas a fim de que possam contribuir para tornar pensáveis os dilemas da humanidade.

\section{Notas}

1. Ver verbete "Culture Wars" em Encyclopedia.com. Disponível em: https://www.encyclopedia.com/religion/legaland-political-magazines/culture-wars. Acesso em: 18 mar. 2020.

2. O ex-Ministro da educação ameaçou as universidades "com balbúrdia" com corte de verbas (ver reportagem da revista Veja de 30 de abril de 2019, disponível no link https://veja.abril.com.br/brasil/universidades-combalburdia-terao-verbas-reduzidas-diz-weintraub/). No Twitter (em 26 de abril de 2019), o presidente anunciou disposição de cortes "em faculdades de filosofia e sociologia [humanas] [...] O objetivo é focar em áreas que gerem retorno imediato ao contribuinte, como: veterinária, engenharia e medicina". No contexto das manifestações, em 15 de maio, o presidente declarou que os estudantes "são idiotas úteis" e "não sabem a fórmula da água" (ver reportagem da revista Carta Capital de 15 maio 2019, disponível no link https://www.cartacapital.com.br/ politica/bolsonaro-manifestantes-sao-imbecis-que-nao-sabem-a-formula-da-agua/). Em 16 de julho de 2019, o presidente, por meio do Twitter, em letras maiúsculas, denunciou a Universidade da Integração da Lusofonia Afro-Brasileira por ter lançado vestibular para "candidatos TRANSEXUAL [sic], TRAVESTIS, INTERSEXUAIS e pessoas NÃO BINÁRIOS” [sic]. A seguir, destacou o papel do MEC, que interveio, viabilizando, desse modo, a suspensão e a anulação do edital. "Nas universidades, os estudantes 'fazem tudo menos estudar"' (ver reportage do site G1 de 12 de dezembro de 2019, disponível no link https://oglobo.globo.com/sociedade/ aluno-de-universidades-brasileiras-faz-tudo-menos-estudar-diz-bolsonaro-24134987)

3. Frente às pressões para tornar a Educação Superior uma atividade lucrativa, é imprescindível que os Estados assumam o compromisso irrenunciável de regular as instituições públicas e privadas, qualquer que seja sua modalidade, e de promover a diversidade institucional, para tornar efetivo o acesso universal, a permanência e a habilitação da educação superior, atendendo a uma formação de qualidade com inclusão, diversidade e pertinências local e regional. [...] A defesa da autonomia universitária é uma responsabilidade incontornável e altamente atual na América Latina e no Caribe e é, ao mesmo tempo, uma defesa do compromisso social da universidade. [...] É por isso que acreditamos firmemente que nossas instituições devem se comprometer ativamente com a transformação social, cultural, política, artística, econômica e tecnológica que é hoje imperativa e indispensável (UNESCO, 2018)

4. A medida provisória (MP) foi devolvida pelo Senado por inconstitucionalidade e, por isso, revogada. O teor do texto em questão pode ser acessado em: http://www.planalto.gov.br/CCIVIL_03/_Ato2019-2022/2020/Mpv/mpv979.htm

5. A primeira versão, divulgada por meio de vídeo (em 17 de julho de 2019), foi denominada Future-se - Institutose Universidades Empreendedoras e Inovadoras. A segunda foi divulgada em 19 de julho de 2019 sob o nome Programa Institutos e Universidades Empreendedoras e Inovadoras - Future-se. A terceira, minuta do Projeto de Lei de 16 de outubro de 2019, passou a ser designada como Programa Universidades e Institutos Empreendedores e Inovadores - Future-se. Os propósitos do empreendedorismo e da inovação sempre estiveram presentes. 
6. Ver Giolo (2020, p. 54). Nos slides apresentados pelo secretário da educação superior, os valores que integrarão o fundo do Future-se estão discriminados desta maneira: 50 bilhões de reais advindos da doação de bens imóveis da União; 33 bilhões retirados dos fundos constitucionais de financiamento das regiões Nordeste, Norte e CentroOeste; 17,7 bilhões oriundos de incentivos fiscais; 1,2 bilhão disputado com a área da cultura (também incentivos fiscais); e 700 milhões obtidos pela utilização econômica do espaço público e dos fundos patrimoniais.

7. “O segundo fato essencial são as restrições orçamentárias ainda mais severas que se impõem em períodos de crise fiscal, como o que se observa no atual momento no Brasil, fazendo-se necessárias medidas como a que vigora na forma do Novo Regime Fiscal" (BRASIL, 2020b).

8. Art. $6^{\circ}, \S 2^{\circ}-$ Os benefícios por resultado compreendem o recebimento de recursos orçamentários adicionais, consignados pelo Ministério da Educação, e a concessão preferencial de bolsas da Coordenação de Aperfeiçoamento de Pessoal de Nível Superior (Capes) às universidades e aos institutos federais participantes do Programa Future-se.

9. Em 2 de agosto de 2019, o diretor do Inpe, Ricardo Galvão, foi exonerado após divulgação de informações obtidas por satélite que desagradaram o Presidente da República. No dia 13 de julho de 2020, no contexto de reformulações do Inpe, que esvaziaram a autonomia científica do órgão, o Ministro da Ciência e Tecnologia, Marcus Pontes, exonerou Lúbia Vinhas, coordenadora-geral de Observação da Terra, pois investidores de fundos de investimentos ameaçaram suspender negócios com o Brasil em virtude do aumento do desmatamento na região (vr reportagem do site G1 de 17 de julho de 2020, disponível no link https://g1.globo.com/politica/noticia/2020/07/13/apos-recordede-alerta-de-desmatamentos-na-amazonia-governo-exonera-coordenadora-do-inpe.ghtml).

10. Art. $8, \S 3^{\circ}-\mathrm{O}$ Poder Executivo federal editará regulamento, conforme proposta a ser apresentada pelo Ministério da Educação e pelo Ministério da Ciência, Tecnologia, Inovações e Comunicações, para dispor sobre o sistema de governança, controle e avaliação de resultados das ações do Programa Future-se.

Art. $9^{\circ}$ - O Programa Future-se será acompanhado e supervisionado por comitê gestor, com composição e funcionamento definidos em regulamento editado pelo Poder Executivo federal.

Art. 11. - O Ministério da Educação e o Ministério da Ciência, Tecnologia, Inovações e Comunicações monitorarão e avaliarão os indicadores de resultado referentes aos contratos de resultado celebrados no âmbito do Programa Future-se.

\section{Referências}

ALEXANDER, J. C. Vociferando contra o iluminismo: a ideologia de Steve Bannon. Sociologia \& Antropologia, Rio de Janeiro, v. 8, n. 3, p. 1009-1023, dez. 2018. https://doi.org/10.1590/2238-38752018v8310

BIRD [Banco Internacional de Reconstrucción y Desarollo]. La ensenãnza superior: las lecciones derivadas de la experiência. Washington: The World Bank, 1995.

BERNHEIM, C. T. La reforma de Córdoba. Vientre fecundo de la transformación. In: SADER, E.; ABOITES, H.; GENTILI, P. (orgs.). La reforma universitaria: desafíos y perspectivas noventa años después. Buenos Aires: CLACSO, 2008. (Colección Grupos de Trabajo.)

BOITO JR., A. A terra é redonda e o governo Bolsonaro é fascista. A Terra é Redonda - eppur si muove..., [s. 1.], 17 out. 2019. Disponível em: https://aterraeredonda.com.br/a-terra-e-redonda-e-o-governo-bolsonaro- 
e-fascista/. Acesso em: 10 jun. 2020.

BRAGGIO, A. K. A gênese da reforma universitária brasileira. Revista Brasileira de História da Educação, Maringá , v. 19, e073, 2019.https://doi.org/10.4025/rbhe.v19.2019.e073

BRASIL, Secretaria-Geral. Ministério da Educação. Ministério da Ciência, Tecnologia, Inovações e Comunicações. Ministério da Economia. Exposição de Motivos n. 00014/2020, Brasília, DF: Secretaria-Geral, 3 abr. 2020a. Disponível em: http://www.planalto.gov.br/ccivil_03/Projetos/ExpMotiv/MECON/2020/14-ME. htm. Acesso em: 20 jul. 2020.

BRASIL. Secretaria-Geral. Projeto de Lei n. 3076/2020, de 2 de junho de 2020. Institui o Programa Universidades e Institutos Empreendedores e Inovadores - Future-se. Brasília, DF: Secretaria-Geral, 2 jun. 2020b. Disponível em: http://www.planalto.gov.br/CCIVIL_03/Projetos/PL/2020/msg302-maio2020.htm. Acesso em: 20 jun. 2020.

CAMBI, F. História da pedagogia. São Paulo: Editora Unesp,1999.

CARVALHO, L. O vírus e a volta do Estado. São Paulo: Todavia, 2020. (Coleção 2020: Ensaios sobre a pandemia.)

CENGAGE. Cultural Wars. In: Encyclopedia.com, [s. l.; s. d.]. Disponível em: https://www.encyclopedia. com/religion/legal-and-political-magazines/culture-wars. Acesso em: 18 mar. 2020. Disponível em: https:// www.encyclopedia.com/religion/legal-and-political-magazines/culture-wars. Acesso em: 18 mar. 2020.

CUNHA, L. A. A universidade reformanda: o golpe de 1964 e a modernização da educação superior. 2. ed. São Paulo: Editora Unesp, 2007.

DARDOT, P.; LAVAL, C. A nova razão do mundo - ensaio sobre a sociedade neoliberal. São Paulo: Boitempo, 2016.

EINSTEIN, A. Escritos da maturidade. Rio de Janeiro: Nova Fronteira, 1994.

FERNANDES, F. Sociedade de classes e subdesenvolvimento. 4, ed. Rio de Janeiro: Zahar, 1981.

FERNANDES, F. A revolução burguesa no Brasil: ensaio de interpretação sociológica. 5. ed. São Paulo: Globo, 2006.

FERRAZ, A. C. C. A autonomia universitária na constituição de 05.10.1988. Revista da Procuradoria Geral do Estado de São Paulo, São Paulo, n. esp., p. 87-124, 1998.

FILGUEIRAS, V.; BISPO, B.; COUTINHO, P. A reforma trabalhista como reforço a tendências recentes no mercado de trabalho. In: KREIN, J. D.; GIMENEZ, D. M.; SANTOS, A. L. (orgs.). Dimensões críticas da reforma trabalhista no Brasil. Campinas: Curt Nimuendajú, 2018.

FINEDUCA [ASSOCIAÇÃO NACIONAL DE PESQUISA EM FINANCIAMENTO DA EDUCAÇÃO]. Atenção: é preciso proteger o financiamento da educação básica dos prejuízos da crise econômica! Nota Técnica sobre a queda das receitas da educação no contexto da pandemia Covid-19 e seus efeitos danosos na manutenção e desenvolvimento do ensino. São Paulo: Fineduca, 7 maio 2020. Disponível em: https:// fineduca.org.br/wp-content/uploads/2020/05/20200507_Nota_queda_-receitas_final.pdf. Acesso em: 20 jul. 2020. 
GIOLO, J.; LEHER, R.; SGUISSARDI, V. Future-se: ataque à autonomia das instituições federais de educação superior e sua sujeição ao mercado. São Carlos: Diagrama Editorial, 2020, E-book. Disponível em: https://www.diagramaeditorial.com.br/project/future-se/. Acesso em: 25 ago. 2020.

GRAMSCI, A. Cadernos do Cárcere. 5. ed. Rio de Janeiro: Civilização Brasileira, 2012. v. 3.

GRUPO DE PESQUISA TRABALHO, PRECARIZAÇÃO E RESISTÊNCIAS. Dossiê sobre o programa Future-se do Governo/MEC e as implicações para a universidade e a sociedade Ver. atual. Salvador: centro de Estudos e Pesquisas em Humanidades (CRH-UFBa), out. 2019. Disponível em: https://drive. google.com/file/d/121dz3Z7UqRaEy3dFIGSwUsBQ42BmDIkw/view. Acesso em: 23 jun. 2020.

HABERMAS, J. A ideia da universidade: processos de aprendizagem. Revista Brasileira de Estudos Pedagógicos, Brasília, v. 74, n. 176, p. 111-130, jan.-abr. 1993. https://doi.org/10.24109/2176-6681. rbep.74i176.1217

HUMBOLDT, W. Sobre a organização interna e externa das instituições superiores em Berlim. In: CASPER, G.; HUMBOLDT, W. Um mundo sem universidades? Rio de Janeiro: EdUerj, 1997.

KREIN, J. D.; GIMENEZ, D. M.; SANTOS, A. L. (orgs.). Dimensões críticas da reforma trabalhista no Brasil. Campinas: Curt Nimuendajú, 2018.

LEHER, R. Universidade e heteronomia cultural: um estudo a partir de Florestan Fernandes. Rio de Janeiro: Consequência, 2018.

LEHER, R. Autoritarismo contra a universidade: o desafio de popularizar a defesa da educação pública. 1. ed. São Paulo: Fundação Rosa Luxemburgo/Expressão Popular, 2019. 232 p. - (Emergências.)

LEHER, R. Guerra cultural e universidade pública: o Future-se é parte da estratégia de silenciamento. In: GIOLO, J.; LEHER R.; SGUISSARDI, V. Future-se: ataque à autonomia das instituições federais de educação superior e sua sujeição ao mercado. São Carlos: Diagrama Editorial, 2020a, Disponível em: https://www.diagramaeditorial.com.br/project/future-se/. Acesso em: 25 ago. 2020

LEHER, R. Esboço de análise sobre o Projeto de Lei do Future-se, Le monde Diplomatique - Brasil, [s. 1.], 17 jun. 2020b, On-line. Disponível em: https://diplomatique.org.br/projeto-de-lei-do-future-se/. Acesso em: 12 jul. 2020

MATTOS, M. B. Governo Bolsonaro: neofascismo e autocracia burguesa no Brasil. São Paulo: Usina Editorial, 2020.

MIGUEL, L. F. O colapso da democracia no Brasil: da Constituição ao golpe de 2016. São Paulo: Expressão Popular, 2019.

MÜLLER, B. F. Por que o bolsonarismo é um fascismo. UOL, Entendendo Bolsonaro, [s. 1.], 30 jun. 2020. Disponível em: https://entendendobolsonaro.blogosfera.uol.com.br/2020/06/30/por-que-o-bolsonarismoe-um-fascismo/?. Acesso em: 10 jul. 2020.

ÖSTILING, J. Humboldt and the modern German University. Lund: Lund University Press, 2018.

PINTO, A. V. O conceito de tecnologia. Rio de Janeiro: Contraponto, 2013. v. 1.

SAAD FILHO, A.; MORAIS, L. Brasil: neoliberalismo versus democracia. São Paulo: Boitempo, 2018. 
SALLES, J. C. Sobre o programa Future-se. A Terra é Redonda - eppur si muove..., [s. 1.], 26 nov. 2019. Disponível em: https://aterraeredonda.com.br/sobre-o-programa-future-se/. Acesso em: 19 jul. 2020.

SALLES FILHO, S. Política de ciência e tecnologia no II PBDCT (1976). Revista Brasileira de Inovação, Campinas, v. 2, n. 1, jan.-jun. 2003. https://doi.org/10.20396/rbi.v2i1.8648872

SOUZA, C. et al. O orçamento das universidades e institutos federais desde 2000. Nexo, [s. 1.], 8 maio 2019. Disponível em https://www.nexojornal.com.br/grafico/2019/05/08/O-or\%C3\%A7amento-dasuniversidades-e-institutos-federais-desde-2000. Acesso em: 21 jul. 2020

UNESCO [UNITED NATIONS EDUCATIONAL, SCIENTIFIC AND CULTURAL ORGANISATION]. Declaración de la III Conferencia Regional de la Educación Superior. Texto apresentado à assembleia da III Conferência Regional de la Educación Superior, Córdoba, Universidad de Córdoba, 14 jun. 2018 Disponível em: http://www.andifes.org.br/wp-content/uploads/2018/06/declaracioncres20181406.pdf. Acesso em: 20 jul. 2020.

VASCONCELOS, G. Interação entre universidade e empresa no país é subestimada. Valor Econômico, Rio de Janeiro, 06 jan. 2020, Disponível em: https://valor.globo.com/brasil/noticia/2020/01/06/interacaoentre-universidade-e-empresa-no-pais-e-subestimada.ghtml. Acesso em: 12 jul. 2020.

\section{Sobre o Autor:}

Roberto Leher é licenciado em Ciências Biológicas pela Universidade Federal do Rio de Janeiro (UFRJ). Doutor em Educação pela Universidade de São Paulo (USP). Professor titular de Políticas Públicas em Educação na Faculdade de Educação da UFRJ. Atua na linha "Educação, Trabalho e Movimentos Sociais" do Programa de Pós-graduação da Faculdade de Educação da UFRJ.

Recebido: 25 jul 2020

Aceito: 10 ago 2020 